\title{
Ética en los medios de comunicación: Prensa, radio, Tv Y cine
}

Ética en los medios de comunicación:

Prensa, radio, TV y cine

Ma. del Mar López Talavera

Barcelona: UOC. 2016

218 páginas

Reseña por Luis Miguel Machín Martín, Universidad de La Laguna
MARIA DEL MAR LOPEZTALAVERA

ÉTICA EN LOS MEDIOS

DE COMUNICACIÓN

PRENSA, RADIO, TVY CINE

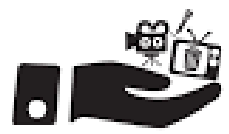

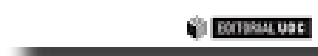

El periodismo como concepto y los medios de comunicación actuales se encuentran muy cuestionados por el público. Tratando de superar su propia crisis interna y sin saber muy bien qué caminos tomar, los medios de comunicación avanzan en direcciones controvertidas, donde ocasionalmente entran en conflicto la deontología periodística y mediática y la lucha por el aumento de la audiencia (o su equivalente digital en clicks, usuarios, sesiones, seguidores o posicionamiento en buscadores).

Esa crisis interna está provocada, en gran parte, por la continua revolución digital a la que los medios están sometidos, haciéndose preguntar continuamente el rol del medio impreso en el mundo digital, el papel del llamado periodista tradicional, o la influencia de la revolución digital en los empleos del mundo mediático y en las tareas que los periodistas y trabajadores en general han de desempeñar, etc.

A esa crisis interna se suma la crisis económica, que es, además, una crisis que integra a su vez otros elementos: crisis de identidades personales y nacionales; crisis del modelo económico; la aparición de nuevas multinacionales del mundo online, que actúan como agentes modificadores no sólo de la economía y el empleo sino de los hábitos de consumo, de comportamiento, etc.; y la crisis de ciertos valores éticos y morales que se presuponían sólidos, y a los 
que la crisis económica y la revolución digital están haciendo tambalear.

En ese contexto surge este Ética en los medios de comunicación: Prensa, radio TV y cine, donde la autora, María del Mar López Talavera, hace un trabajo exhaustivo de integración de una gran cantidad de problemas éticos y deontológicos relacionados con los medios de comunicación. Aunque está planteado como un libro de invitación a la reflexión sobre la ética en los medios de comunicación también puede verse como un manual de deontología, puesto que, lejos de de ceñirse al presente y rehuir de precedentes, el libro busca en las raíces mismas de la ética y la moral algunas de las soluciones a los problemas existentes en los medios actuales. Además, y pese a no ser exclusivamente un libro destinado a la enseñanza, sí parece estar planteado como un manual dirigido a alumnos y a profesionales de la comunicación. Posee una amplia carga teórica pero también práctica, vocación que se manifiesta, además, con la inclusión de estudios de caso y ejemplos que plantean diversos problemas éticos en todo tipo de medios de comunicación, siendo abordados desde variadas perspectivas. Así, a través de estos ejemplos, se plantean preguntas directas sobre la ética de los profesionales de los medios, preguntas que sirven no sólo como examen sino como reflexión.

Los casos prácticos sirven para dar solidez a todos los dilemas que la autora va planteando. Así, se recogen casos conocidos como el de Omayra Sánchez, que falleció agónicamente atrapada en un lodazal provocado por el volcán Nevado del Ruiz, en Colombia, y fue grabada y fotografiada incesantemente hasta su muerte. O el de Ylenia Carrisi, hija del cantante italiano Albano, quien según la versión oficial había desaparecido y fallecido, pero que, según afirmó una periodista española más tarde, seguía viva, hipótesis que nunca se demostró y para la que nunca se llegaron a aportar pruebas contundentes. También hay espacio para polémicas y dilemas surgidos en espacios de la televisión española como Crónicas marcianas o Esta noche cruzamos el Mississippi, que poblaron los horarios nocturnos durante buena parte de la década de los 90.

Ética en los medios de comunicación: Prensa, radio TV y cine va de lo general a lo particular, partiendo de conceptos generales como ética, moral o qué son los valores, y los acaba enfocando al contexto particular español, como hemos visto. Así, por ejemplo, enumerando las razones de periodistas y comunicadores para no ser éticos, afirma: "Unas veces, el rechazo a la ética se debe a la memoria histórica, es decir, a razones que corresponden al pasado de la historia del periodismo y a la historia de España propiamente", (p. 47). De esta forma, no sólo usa ejemplos concretos de sucesos mediáticos -algunos más conocidos e impactantes que otros- sino que emplea todo el contexto histórico y geográfico de España para construir un manual aplicado al país, lo que le aporta un valor añadido sobre otro tipo de monográficos sobre deontología y ética que no den una visión tan concentrada en este territorio.

El libro está estructurado de modo que pueda leerse como una obra coherente, donde cada nuevo capítulo recoge el testigo del anterior, pero que, al mismo tiempo, pueda resolver dudas concretas en un capítulo sin tener que recurrir a los anteriores. Los dos primeros capítulos sirven como introducción teórica para los siguientes, donde esa conceptualización ética pasa a aplicarse a diversos contextos y profesiones. Uno de los 
elementos que pueden pasar desapercibidos pero que es destacable es su abundante aportación bibliográfica al final de cada capítulo, que no sólo refleja una documentación y conocimientos exhaustivos de la materia, sino que muestran una voluntad de diálogo con otras fuentes de la misma materia.

Ética en los medios de comunicación: Prensa, radio TV y cine es una actualización adaptada al contexto español de la aplicación de conceptos éticos y deontológicos para profesionales de los medios de comunicación. Pero es, también, un manual de consulta para estudiantes y un recorrido elemental a las bases del campo de la ética enfocadas al mundo de la comunicación. El libro es, por tanto, una aportación que surge en el momento justo dentro de un contexto de gran inestabilidad social y laboral, donde se hace especialmente necesario recordar las implicaciones éticas de las decisiones que los profesionales en medios tienen que tomar. 